\title{
Patterns to scientific internationalism: What can a comparative history of IAU and IUPAP teach us?
}

\author{
Roberto Lalli \\ Max Planck Institute for the History of Sciene \\ Boltzmannstr. 22, 12047, Berlin, Germany \\ email: rlalli@mpiwg-berlin.mpg.de
}

\begin{abstract}
International scientific institutions are preferred settings to explore prominent topics in the transnational approaches to the recent history of science. These include: the dichotomy between universalism and contextualism in the historical evolution of exact sciences; the historical transformation of the ideals of scientific internationalism; the tensions between these historically changing ideals and scientists' national allegiances; the balance between scientific and diplomatic activities of such institutions; and the issue of how the complex ideological, socio-political roles these institutions play affected the actual evolution of science.

Inspired by these overreaching themes, the paper presents a conceptual framework for pursuing a comparative analysis of IAU and IUPAP. A bird's-eye view of the parallel historical developments of these two unions shows that, in spite of their common origins in the highly politicised context of the post-WWI reconstruction of international cooperation, IAU and IUPAP followed diverging trajectories in many respects. It is argued that a deeper study of these differences might give important insights to properly understand the relevance of specific disciplines' scientific needs in the way the ideals and practices of scientific internationalism were actualised through the 20th century.
\end{abstract}

Keywords. IUPAP, science diplomacy, scientific internationalism

\section{Introduction}

The International Astronomical Union (IAU) was founded on 28 July 1919 under the umbrella of the newly established International Research Council (IRC) in the highly politicised context of the post-WWI (re-)construction of international scientific cooperation. Together with the International Union of Geodesy and Geophysics, IAU was the first union to be created in this context. In many relevant aspects - including its legal, administrative and organisational structure as well as its delicate relations to the political contexts - the IAU could provide a model for the international unions on various disciplines that would be created in the next few years, including the International Union of Pure and Applied Physics (IUPAP), which would be established in 1922.

In spite of the common historical background, a bird's-eye view at the parallel historical developments of IAU and IUPAP shows that they followed diverging trajectories in many crucial aspects of their activities. These differences include: different responses to similar political contexts; different relationships with IRC and its successor organisation, the International Council of Scientific Unions (ICSU); different ways in which the two institutions defined and addressed the issues of national and individual memberships; different interpretations of the role and the structure of the unions, which is evident in 
the nature and work of the two unions' commissions; the different impact and importance the two unions had on the evolution of the disciplines they were devoted to. These somewhat surprising divergences signal that the ideals and practices of scientific internationalism during the 20th century varied greatly in their institutional representations, which in turn suggests that specific scientific needs of the various disciplines played a fundamental role in the historical actualisation of these ideals.

In the paper, I aim to address this issue in a programmatic fashion from an historiographical perspective. Rather than presenting research results from on-going or completed studies, I shall put forward a conceptual framework for a comparative analysis of the historical evolution of IAU and IUPAP. I do so by, first, spelling out the larger historiographical issues the proposed comparative analysis should be embedded in, and, secondly, by discussing some of the most revealing differences between the two unions' structures and historical evolutions. The proposed comparative approach results in a set of questions that need to be answered by future studies, which necessarily require fruitful collaboration between science historians and professional scientists, both in astronomy and physics.

\section{Broader historiographical themes: Why is an historical research on international scientific institutions needed?}

The ways in which non-governmental international organisations have tried to implement the ideals of scientific internationalism during the 20th century are of the utmost importance for many broad issues central to the transnational historiography of science.

The first issue concerns the dichotomy of universalism and contextualism in the exact sciences: while, on the one hand, exact sciences aspire to universality by virtue of their rigorous formal and experimental methods, on the other hand, like any human activity, they depend on situated historical and political contexts. Since the 1970s social approaches to the history of science have challenged the view that science is epistemically universal and one has seen a dominance of studies focusing on the local dimension as central to the evolution of science (e.g. Shapin 1995; Golinski 1998). Recently, historians of science have tried to combine a realistic, sociologically inspired picture of science development with the transnational dimension of science's universalistic stance (e.g. Pyenson 2002; Turchetti et al. 2012). These efforts have come to see the activities of international scientific institutions as particularly fruitful in the attempts to overcome this traditional conflict that has had a strong impact on the evolution of the history of science (Froengsmyr 1990; Crawford et al. 1993; Elzinga 1996; Krige \& Barth 2006a; Oertzen 2014).

The second, related theme deals with the historical transformation of the ideal and practices of scientific internationalism. That of scientific internationalism is a pervasive ideology in the activities and training of most scientists, which is in part related to the widespread belief that exact sciences are universal (e.g. Feinberg 1998). On the other hand, various studies have shown that scientific internationalism has a troubled history. First of all, as an ideal, scientific internationalism underwent profound changes in dependence to broader cultural, social and political transformations: Marx-inspired internationalism spreading in the late 19th century was deeply different from the liberal and imperialistic internationalist discourse that gained momentum in the early 20th century, in turn different from the post-World War II ideals of one-world government shaping the creation of the United Nations (UN) (e.g. Elzinga \& Landstrom 1996; Somsen 2008; Sluga 2013).

Secondly, these ideals have always been in constant tensions with the national allegiances of scientists and the related political and economic interests (e.g. Forman 1973; 
Schroeder-Gudehus 1978, 1990; Fox 2016). In specific periods, scientists have explicitly addressed this tension. More often, however, this contrast has remained implicit in the actions of scientists who knew the relevance of sensible, restricted or even secret knowledge in international exchanges (e.g. Dongen 2015). The activities of scientific international institutions present illuminating examples of the tension between internationalist ideals and the relevance of national interests, and thus are particularly suited to uncover hidden mechanisms on the relation between the historically changing ideals of scientific internationalism and their applications in a politically divided world.

Given the relevance of national interests in the establishment and functioning of international scientific institutions, one of their prominent roles became to represent venues for scientists' state-based diplomatic efforts, whose complex history is still to be explored (Doel 1997; Krige \& Barth 2006b; Doel \& Harper 2006; Turchetti et al. 2012; Dongen 2015). In this perspective, a study of their historical evolution illuminates the way the sciences have been employed as diplomatic tools by governments, and, on the other side, how scientists dealt with political matters in the attempts to pursue their scientific targets.

The last issue, which is naturally related to the previous ones, is to understand how all this affected, and was affected by, scientific developments. A transnational approach to the history of recent sciences entails an attention to the variety of political, ideological, epistemological and diplomatic activities of international scientific institutions. On the other hand, the mission of international unions is clearly to foster international cooperation for the advancement of specific disciplines. The precise relation between the scientific mission of these institutions and the set of parallel, different roles they played, show how the evolution of science was entangled with more general discourses, not necessarily related to purely scientific aspects.

\section{Rationale for a comparison}

The issues discussed above clearly show the relevance of deepening our historical knowledge of international scientific unions, but my proposal goes further so as to perform a comparative analysis between different international unions, which might give relevant insights on the above-mentioned themes.

The history of the international unions is deeply related to the history of the overreaching institutional body that was constructed for coordinating international cooperation in scientific research from the end of World War I onwards, namely, the IRC, which was re-organised in 1931 under the name of ICSU (Greenaway 1996). In the early process of the IRC construction, it was envisaged to establish various unions devoted to different scientific disciplines. The IAU was the first of such unions to be established together with the International Union of Geodesy and Geophysics (IUGG). This happened at the very first general assembly of the IRC, so that one might fairly say that the IAU was constituted together with the IRC itself and was plausibly seen as the model of the disciplinary unions that were proposed. Even though the unions were clearly connected by the IRC institutional umbrella, the IRC statutes contained no regulations concerning the structure and function of the unions themselves. One cannot even find any attempt at defining the meaning of the unions in any specific way, which means that they were left free to follow their own organisational and legal patterns. As a consequence, international unions showed relevant differences since their establishment and followed quite divergent patterns.

A focus on four aspects drawn from the parallel historical developments of the IAU and IUPAP serve to highlight the character and import of these deep differences. I argue that these differences, if investigated further, might tell us a lot on the way the ideals 
and practices of scientific internationalism, and the related issues of science diplomacy, were connected to specific needs and practices of different scientific disciplines.

\subsection{Genetic connection (and early deviations)}

The very first difference is the year of their establishment: Why was IAU established earlier than the union devoted to physics? A response one finds in historical analyses is that astronomy (like geodesy and geophysics) has intrinsic characteristics of internationalism that other disciplines did not have to the same degree. As argued by Crawford et al. (1993), among others, national boundaries for these kinds of disciplines are simply unhelpful constraints that need to be overcome in order for a research to be properly and fully realised. These needs had led astronomers to pioneer some among the first large international projects ever established in the 19th century such as the Carte du Ciel project. In fact, the gained experience in cooperative practices at the international level led to the creation of a pre-WWI international union: the International Union for Cooperation in Solar Research (Solar Union). Established in 1905, the Solar Union was probably the very model followed in the creation of post-WWI disciplinary unions (Blaauw 1994). It is then very plausible that intrinsic features of astronomical research had led to the astronomers' priority in the institutional re-organisation after World War I, which was initially based on pre-war established networks. I would suggest, however, that there are other different, albeit connected, reasons.

One of these might be the organisational structure of astronomical observatories, especially in the United States (Lankford 1997). The suggestion is that the large, multi-disciplinary, management-based and goal-oriented organisational structures of such observatories enabled astronomers, and especially large observatories' directors, to recognise that centralised coordination of research was essential to meet the scientific and technological demands of the First World War. This seemed to happen in the US, with the director of the Mount Wilson Observatory, George Ellery Hale, playing a leading role in the establishment of the National Research Council (Wright 1994). It is well known that Hale's ideas, as well as his personal and institutional networks, were also instrumental in launching and shaping the IRC, as well as the related national re-organisation of scientific research in most allied countries in the immediate aftermath of WWI (Blaauw 1994). The important role of astronomers in shaping the scientific landscape based on their previous large-scale collaborations was plausibly central in conceiving of the structure of disciplinary unions, and this role is reflected in the chronological priority IAU had with respect to other unions.

Under the hypothesis that IAU served as a model for the creation of other unions, one might then ask whether large-scale astronomical observatories were also implicitly taken as models by those physicists involved in the foundation of IUPAP. Or, by contrast, did the working environments and practices of physicists lead to implement a quite different structure and organisation?

The genesis of the two institutions also presents another intriguing difference, which might be conceptualised as the opposition between continuity and discontinuity. While the IAU was a continuation of pre-war experiences, like the Solar Union, IUPAP was essentially created from scratch. From this quite substantial difference in the origins of the two unions, a number of sensible questions arise: To what extent was the IAU a continuation of astronomers' previous experiences? Can one imply that IUPAP was, in comparison, somewhat artificial in its establishment, following institutional models of international collaborations developed in other disciplines? How far did the strong difference in the genesis of the two unions lead to develop two different roles and functions for the two unions? 


\subsection{Science and politics}

In drafting the regulations of the IRC and of all international unions, political considerations played a prominent role. This is clearly evident in the exclusion of the Central Powers and in the delay with which neutral countries were admitted. The regulation that membership had to be connected to the notion of national representation was also a consequence of the political climate after WWI, as it allowed the implementation of the decision to exclude the Central Powers' scientists (Blaauw 1994; Greenaway 1996). In this respect, it seems that all unions were coherent, as they all followed a scheme that dominated the construction of the IRC and its early developments.

In spite of this strong communality, in other cases the IAU and IUPAP showed strong divergences concerning the relations between the changing political landscape and their memberships. The most striking example relates to the participation of the Soviet Union in such bodies. While the policy of excluding Central Powers' scientists was legally binding in the initial statutes and by-laws of the IRC and of the various unions, the relations with the Soviet Union was not explicitly regulated. Under Joseph Stalin's rule, the Soviet Union did not participate in the great majority of scientific international organisations. By far and large, only after Stalin's death in 1953, did Soviet scientists start participating in international organisations as USSR delegates. As examples, the Soviet Union became a member of UNESCO and ICSU in 1954, and only three years later, in 1957, did it officially join IUPAP.

The IAU was, instead, clearly an exception. The IAU counted the Soviet Union among its members since 1935. Namely, the Soviet Union became an IAU member just at the outset of the 'Great Purge' campaign, which is usually credited as the period in which Soviet scientists were generally forced to disrupt their international contacts (e.g. Josephson 1991). In the immediate post-World War II period, when Soviet scientists were still prevented from participating in any international meetings and organisations, Soviet delegates were actively involved in IAU meetings and post-war reconstruction efforts (Ivanov 2002).

This disparity between the unions and the peculiarity of the IAU raise questions concerning the reasons why similar international institutions acted differently in the same political circumstances. Why was astronomy so special as to result in the IAU having such a radical departure concerning Soviet participation? An understanding of this problem might shed light on the specific role of astronomy in the diplomatic activities among scientists working in different ideological and political systems.

\subsection{National and individual membership}

The focus on membership provides another aspect of reflection on the diverging patterns of the attempts at realising the ideals of scientific internationalism in such institutions. In her study of the transformation of the internationalist discourse, Glenda Sluga (2013) defines important historical phases in which the ideals of internationalism became relevant in the diplomatic activities to build peace and mutual understanding among peoples. In these different historical phases, this discourse was embodied in the actual construction of institutional structures to define the priorities of the international agreement, most often legal, but also cultural and moral. The international unions were certainly embedded in these general trends, as can also be seen by their increasing connections with larger, and more bureaucratised, institutions, such as UNESCO from 1946. To put it briefly, Sluga argues that this trend was characterised by the fact that cosmopolitan ideals were subordinated to national interests in the daily activities of international institutions. In this trend, nation-states and their interests came to play fundamental roles in the functioning of international institutions and greatly influenced the activities, first, 
of the League of Nations and, later, of the United Nations. International unions were no exception to this rule: since their inception, they were mostly understood as state-based diplomatic activities. This was made possible by the original idea that membership in such unions was based on the concept of national representation.

Even in this case, however, one notices a big difference in later developments. The notion of national membership was not clearly defined until 1983, when it was legally clarified in the changes of the statute of ICSU (Blaauw 1994; Greenaway 1996). It is then not surprising that the various unions used different concepts of national membership in their statutes and that these developed differently over the decades. It is even more interesting that, while IUPAP has always been, and still is, a union based on the concept of national membership - whatever it meant in different historical phases - the IAU diverged from this rule by accepting individual members. In this sense, the IAU has assumed a structure more similar to a hybrid association. The questions then arise as to why institutions with a common origin came to interpret in such different ways the notion of membership and why they showed such divergent paths in the openness to non-national members. Although one might certainly interpret these divergent paths as related to local circumstances, it is more fruitful to reflect upon those features of the different scientific disciplines that might be connected to such a strong difference.

\subsection{The function and scope of commissions}

Finally, the structure itself of these unions presents relevant variants. All unions originated by a common need for centralised organisational structures for promoting international cooperation in a goal-oriented fashion, which could also improve academyindustry relationships. World War I had made evident the fruitfulness of such structures, and the case was made for promoting these organisations as essential to national civil and military developments (Tobey 1971). In spite of the common origin, the implementation of this idea materialised differently in the various unions. This is particularly evident in the creation and activities of the commissions.

The activity of the IAU was immediately characterised by the creation of 32 commissions of experts, which were devoted to specific scientific problems. Crawford et al. (1993) have argued that the main role of international scientific institutions is to provide certified methodologies for creating standards, which might be at the various levels of the scientific enterprise, as they concern notions, methods, communication means and technologies. International institutions have been endowed with the authority to provide and stabilise those standards at the global level. The way the IAU implemented this mission was by means of active commissions that were aimed at solving various problems that touched the full spectrum of the standardisation activities identified by Crawford et al. (1993), from bibliographical problems, to measurement issues up to specific topics that had conceptual and methodological relevance (as, e.g., Commission No. 1 on Relativity). This activity seems to signal that IAU officials interpreted the role of the institution as an inclusive board for the formation of common shared views on relevant scientific problems for the advancement of the discipline.

The structure of IUPAP was completely different. In the first three decades of its existence, IUPAP had only three commissions. The first one worked on the finances of the union; the second focused on publication issues; the third, and perhaps most important, commission was called the SUN Commission, as it was devoted to the problems of defining symbols, units and nomenclature. This means that before the 1950s, IUPAP limited itself to the standardisation of measurement units as well as the means of communication and it renounced any attempts to delve into specific conceptual problems, or sub-disciplinary developments. 
This deep structural difference suggests that astronomers and physicists had quite different views on what functions institutionalised forms of international cooperation should fulfil. Most probably, this difference was not simply the result of diverging personal opinions, but one should ask how these differences were related to the specific needs of the two disciplines.

As a result of this perspective, one might see if the dramatic transformations in the organisation of the sciences occurring during the 20th century were reflected in the structures of different unions, or how quick the unions were in integrating these changes into new organisational structures. A crucial period of investigation certainly is the postWorld War II period. In the immediate aftermath of World War II, the structure of IUPAP changed radically, by including more commissions, which were directed to specific sub-disciplines and research areas, such as cosmic rays, low-temperature physics, solid-state physics and acoustics. As a consequence, IUPAP assumed a different function from the one it fulfilled in the previous decades. In the same post-WWII period, the change in the IAU was not particularly relevant, as far as the role and number of commissions are concerned, and one can see a more clear continuity between the IAU's activities pre- and post-WWII.

The clarification of the reasons behind different historical developments might lead to a better understanding of how the changing working environments of scientists affected the structure of the unions. In this context, one hypothesis to be explored is whether the growth of big-science endeavours in physics was the leading force behind the transformation of IUPAP, whose structure became possibly more similar to that of the IAU in the post-WWII period.

\section{Conclusion}

In embedding a comparative analysis of the IAU and IUPAP in major themes in the transnational approaches to the history of science, I have argued that this study might lead to a clearer understanding of how topics such as scientific universalism, internationalism and diplomatic activities were articulated differently by scientists working in different disciplinary domains. The enormous differences - which appear with a bird'seye view of the parallel development of the two institutions - suggest that the specific needs of different scientific disciplines radically affected the way in which such ideals were realised in practice. It is the hope of the present author, that future studies will be able to further clarify these issues, as well as the related relevance of the two unions' activities in the development of astronomy, physics and astrophysics.

\section{References}

Blaauw, A. 1994, History of the IAU: the birth and first half-century of the International Astronomical Union (Dordrecht: Kluwer)

Crawford, E., Shinn, T. \& Sörlin, S., 1993, in: E. Crawford, T. Shinn, \& S. Sörlin, S., The Nationalization and Denationalization of the Sciences (Dordrecht: Springer), p. 1

Doel, R. 1997, in: T. Söderqvist The historiography of contemporary science and technology (Amsterdam: Harwood), p. 215

Doel, R. \& Harper, K. 2006, Osiris, 21, 66

Dongen, J.v. (ed.) 2015, Cold War Science and the Transatlantic Circulation of Knowledge (Berkeley: Brill)

Elzinga, A. \& Landstrom, C. (eds.) 1996, Internationalism and Science (London: Taylor)

Elzinga, A. 1996, in Elzinga \& Landstrom (1996), p. 3

Feinberg, E. L. 1998, in: V. Stefan Physics and society: essays in honor of Victor Fredrick Weisskopf by the international community of physicists (New York: AIP Press), p. 83

Forman, P. 1973, Isis, 64, 151 
Fox, R. 2016, Science without frontiers: cosmopolitanism and national interests in the world of learning, 1870-1940 (Corvallis, OR: Oregon State University Press)

Fröngsmyr, T. (ed.) 1990, Solomon's House Revisited. The Organization and Institutionalization of Science (Canton: Science History Publications)

Golinski, J. 1998, Making natural knowledge: constructivism and the history of science (New York: Cambridge University Press)

Greenaway, F. 1996, Science international: a history of the International Council of Scientific Unions (Cambridge: Cambridge University Press)

Hollings, C. 2016, Scientific Communication Across the Iron Curtain (Charm: Springer)

Iriye, A. 2002, Global community: the role of international organizations in the making of the contemporary world (Berkeley: University of California Press)

Ivanov, K. 2002, Sci. Context, 15, 317

Josephson P. 1991, Physics and politics in revolutionary Russia (Berkeley: University of California Press)

Krige, J. \& Barth, K.-H., (eds.) 2006a, Global Power Knowledge: Science and Technology in International Affairs (Chicago: University of Chicago Press)

Krige, J. \& Barth, K.-H., 2006b, in Krige \& Barth (2006b), p. 1

Lankford, J. 1997, American astronomy: community, careers, and power, 1859-1940 (Chicago: University of Chicago Press)

Laqua, D. 2011, J. Global Hist., 6, 223

Oertzen, C.v. 2014, Science, gender, and internationalism: women's academic networks, 1917-1955 (New York: Palgrave)

Pyenson, L. 2002, Hist. Sci., 40, 251

Shapin, S. 1995, Annu. Rev. Sociol., 21, 289

Schroeder-Gudehus, B. 1978, Les scientifiques et la paix: la communauté scientifique internationale au cours des années 20, (Montréal: Presses de lÚniversité de Montréal)

Schroeder-Gudehus, B. 1990, in R.C. Olby, G.N. Cantor, J.R.R. Christie, \& M.J.S Hodge Companion to the History of Modern Science (New York: Routledge)

Sluga, G. 2013, Internationalism in the age of nationalism (Pittsburgh: University of Pittsburgh Press)

Somsen, G. 2008, Minserva, 46, 361

Tobey, R. 1971, The American ideology of national science, 1919-1930 (Philadelphia: University of Pennsylvania Press)

Turchetti, S., Herran, N., \& Boudia, S. 2012, Brit. J. Hist. Sci., 45, 319

Wright, H. 1994, Explorer of the universe: a biography of George Ellery Hale (Woodbury: AIP Press) 